\title{
Selective Serotonin Reuptake Inhibitors (SSRIs) with Dual Functionality; Hybrid Anti-Autism Candidates
}

\author{
Ola Maher Ghoneim*, Reem Hasan Elajez and Hebatalla Mahmoud Afifi
}

\author{
College of Pharmacy, Qatar University, P.O box 2713, Doha, Qatar
}

\begin{abstract}
Autism is a lifelong neurodevelopmental disorder significantly on the rise worldwide. Prevalence rate increased dramatically from 1 case/10000 in the early 90's to 1 case/110 in 2011. The diagnosis is characterized by three main domains: dysfunction in social interaction, communication impairment and repetitive behaviors. Selective Serotonin Reuptake Inhibitors (SSRIs) are currently the drug class of choice for treating autism symptoms. The major drawback of SSRIs is that they take several weeks to become therapeutically efficient. Co-administration of SSRIs with 5-HT $1 \mathrm{~B} / 1 \mathrm{D}$ receptor antagonists proved to be advantageous over SSRIs alone with respect to the magnitude of brain serotonin levels produced. The theory is that the acute blockade of 5-HT $1 \mathrm{~B} / 1 \mathrm{D}$ receptor would prevent the negative feedback these autoreceptors exert normally on serotonin release and hence enhance the efficiency of SSRIs (i.e. synergistic effect).

We hypothesize to incorporate the dual pharmacophoric profile of serotonin reuptake inhibition and 5-HT $1 \mathrm{~B} / 1 \mathrm{D}$ antagonism in one single molecule carrying dual functionalities. A library of 12 virtual hybrids was successfully designed. The organic synthesis of two chosen hybrids was completed with full structure elucidation, including elemental analysis and proton-Nuclear Magnetic Resonance.

The main outcome of the study is obtaining an unprecedented library of novel hybrid molecules combining serotonin reuptake inhibition with $5 \mathrm{HT}_{1 \mathrm{~B} / 1 \mathrm{D}}$ antagonism in one single molecule. In addition, establishing chemical synthesis and other foundation materials needed for further investigation (In vitro and in vivo pharmacological evaluation) towards our ultimate goal of developing new therapeutic line of autism, where no other lines of treatment have been consistently successful.
\end{abstract}

Keywords: Autism, Autoreceptors, Dual Functionality, Hybrid Molecules, Serotonin, Selective Serotonin Reuptake Inhibitors, Serotonin 5-HT1B/1D antagonist.

\section{BACKGROUND AND SIGNIFICANCE}

Autism is a lifelong complex neurodevelopmental disorder significantly on the rise worldwide. Prevalence rate increased dramatically from 1 case per 10000 children in the early 90's to 1 case per 110 in 2011 as estimated by the National Survey of Children's health [1]. Nearly 300,000 Children aged 4-17 had received a diagnosis of autism in USA alone in 2004. There are no confirmed statistics about the number of children with autism in Qatar. However, the previous statistics set an alarming call about the number of individuals with autism in Qatar either already diagnosed or yet to be diagnosed.

The American Psychiatric Association in 2000, defined autism as a disorder that affects the development of young children [2]. The diagnosis is characterized by three main domains: (i) Dysfunction in Social interaction (ii) Impairment in language and Communication (iii) Repetitive behaviors and restricted interests. The last domain includes obsession towards particular object(s), phrase(s), and/or body movement(s) e.g. rocking head back and forth, or flapping hands. It also involves the very strict adherence to a rigid routine schedule which might manifest in the food they

*Address correspondence to this author at the College of Pharmacy, Qatar University, P.O box 2713, Doha, Qatar, Tel: +974-6605-6756; Fax: +9744403-5551; E-mails: olaag@qu.edu.qa,ola.ghoneim11@gmail.com eat (only food with a specific color or texture), the clothes they wear (only clothes made of specific fabrics), etc. Frequency and severity of the repetitive behavior vary from one patient to another. Consequently, repetitive behaviors domain significantly interferes with simplest tasks of daily living, educational and social learning, and negatively affect the individual's quality of life and relationship with others. Until now, no primary drug has been consistently effective in treating repetitive behaviors.

Selective Serotonin Reuptake Inhibitors (SSRIs) are currently the drug class of choice for treating autism symptoms including repetitive behaviors. SSRIs are originally antidepressant agents with established efficacy for the management of depression, anxiety, obsessive compulsive disorder and recently employed for treating repetitive behavior symptoms in autistic children [3]. On one hand, a supportive body of evidence indicates that SSRIs are capable of reducing or modulating symptoms of repetitive behaviors in autistic patients although the exact mechanism might not be quite clear $[3,4]$. On the other hand, and as major drawback, it takes 4-6 weeks for an SSRI to become therapeutically efficient. This drawback/delay in efficiency plus other potential side effects notably irritability and insomnia vary from one patient to another and significantly decrease patient compliance, and increase anxiety level. Furthermore, the delay adds more pressure and confusion to 
the patient's family about the effectiveness of the undergoing therapy.

One possible explanation of the delay in efficiency is attributed to the mechanism by which SSRIs operate. SSRIs inhibit binding of serotonin (5-HT) to its transporter, block its reuptake, and increase the magnitude of 5-HT in the synaptic cleft. This elevated level of 5-HT, in turn, stimulates 5-HT receptors to initiate a cascade of effects and relieve the symptoms of repetitive behaviors. However, the elevated 5-HT level also stimulates inhibitory autoreceptors $\left(5-\mathrm{HT}_{1 \mathrm{~B} / 1 \mathrm{D}}\right)$ which by definition, regulate the release of 5-HT in an inhibitory manner and negatively affect the mode of action of SSRIs [5,6]. It is, thus, anticipated that coadministration of SSRIs with 5- $\mathrm{HT}_{1 \mathrm{~B} / 1 \mathrm{D}}$ receptor antagonists to be advantageous over SSRIs alone with respect to the magnitude of extracellular brain 5-HT levels produced [7-9]. The theory is that the acute blockade would prevent the negative feedback these autoreceptors exert normally on 5HT release and hence enhance the efficiency of SSRIs and result in a synergistic effect [7-9] (Fig. 1).

Taken together, SSRIs and $5 \mathrm{HT}_{1 \mathrm{~B} / 1 \mathrm{D}}$ autoreceptors are two key players involved in the cause and/or treatment of repetitive behaviors in autism. Therefore, in order to develop a potential therapy for repetitive behaviors, we can combine an SSRI with 5- $\mathrm{HT}_{1 \mathrm{~B} / 1 \mathrm{D}}$ antagonism via combination therapy (i.e. co-administration of 2 compounds) to increase the efficiency of SSRIs. This approach proved to be successful as previously described [9-10]. Alternatively, we can incorporate these two key components (5-HT reuptake inhibition and 5- $\mathrm{HT}_{1 \mathrm{~B} / 1 \mathrm{D}}$ antagonism) in one hybrid molecule (i.e. one single drug) carrying their dual functionality. Benefits of the proposed hybrid molecules include, but not limited to, develop a fast acting SSRI, avoid the cost of synthesizing/marketing two drugs, avoid potential dose/side effects that arise from administrating two concomitant drugs, and finally increase patient compliance by taking on drug instead of two. Similar approach has been successfully reported with depression [11-13]. However, to the best of our knowledge, this is an unprecedented potential therapeutic avenue for autism.

\section{OBJECTIVES}

The main objectives of this research project are:

2.1 To design at least FIVE virtual hybrid molecules by combining the pharmacophoric elements of 5-HT reuptake inhibition with $5 \mathrm{HT}_{1 \mathrm{~B} / 1 \mathrm{D}}$ antagonism in one single molecule(s).

2.2 To synthesize ONE hybrid molecule carrying the dual pharmacophoric profile of 5-HT reuptake inhibition with $5 \mathrm{HT}_{1 \mathrm{~B} / 1 \mathrm{D}}$ antagonism.

\section{STUDY DESIGN AND METHODOLOGY}

\subsection{Design a Small Library of Virtual Hybrid Molecules}

The strategy of designing virtual hybrid molecules combining the pharmacophoric profiles of 5-HT reuptake inhibition with $5 \mathrm{HT}_{1 \mathrm{~B} / 1 \mathrm{D}}$ antagonism in one molecule can be conducted via: I) Modification of already existed hybrid molecules previously made by other research groups or II) the tethering technique or fragment based drug discovery. Tethering technique links two molecular scaffolds (believed to be responsible for the targeted biological activity) together through their tolerable areas via a linker. The chosen linker has to be able to metabolized and break down inside the body. Examples of such linkers are amide or ester linkage.

Our design approach initiated by collecting literature information pertaining to structure activity relationship (SAR) of the two desired pharmacological classes; serotonin reuptake transporter (SERT) inhibitors and $5 \mathrm{HT}_{1 \mathrm{~B} / 1 \mathrm{D}}$ receptors inhibitors. Then, key pharmacophoric elements and/or molecular scaffold believed to be responsible for the desired biological activity in the receptor/transporter under study were revealed, studied and analyzed. In addition, previously made hybrid compounds by other research groups were identified (Fig. 2).

\subsubsection{Designing the " $R$ " Series}

Designing the " $\mathrm{R}$ " series is based mainly on modification of the main skeleton of the newly discovered molecule by Bromidge et al., Glaxosmithkline research group in the UK (Fig. 2) [14-15] as a potential, novel, orally bioavailable,

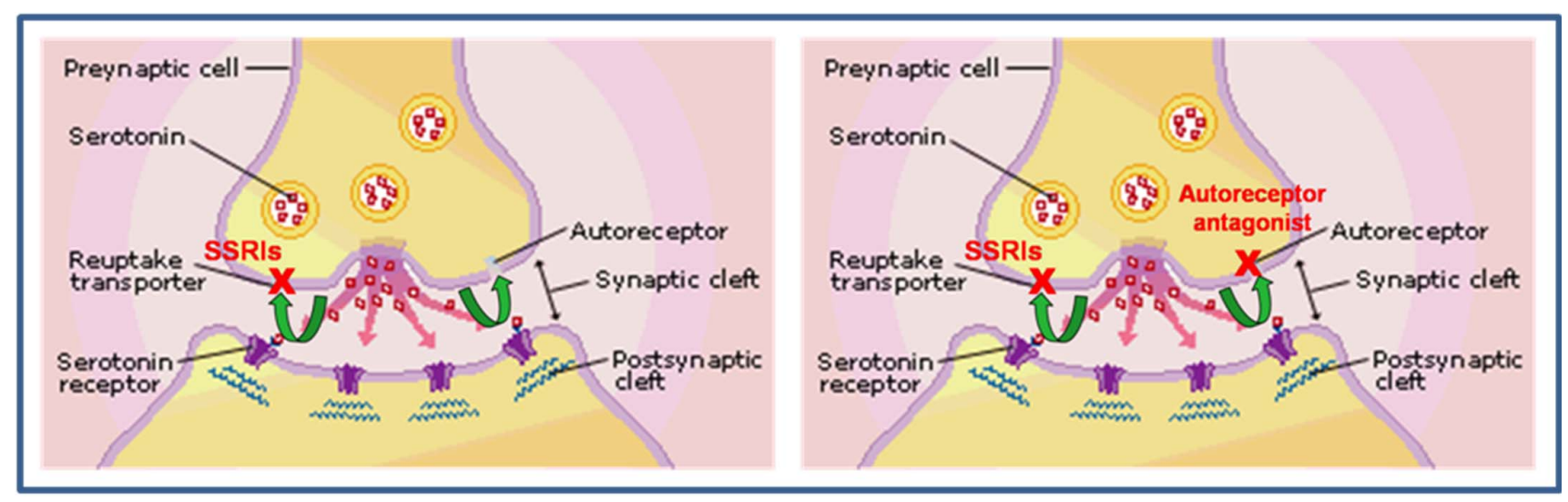

Fig. (1). Predicted mechanism of action of SSRIs in the absence (left) and presence (right) of autoreceptor antagonists. Green arrows show the two pathways for serotonin regulation by both reuptake transporter and autoreceptor. Figure on the left shows continuous opening of the autoreceptor counteract SSRI mode of action, causing delay in their therapeutic effect (antagonism). Figure on the right shows the blockade of the autoreceptor by autoreceptor antagonists, preventing their normal negative feedback, and accelerating the therapeutic efficiency of SSRI (synergism). 

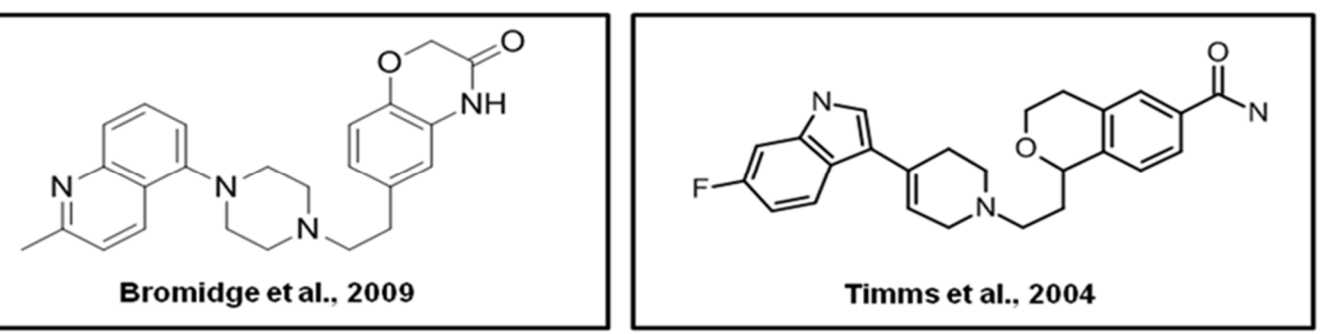

Fig. (2). Previously made hybrid molecule combining 5-HT reuptake inhibition and 5-HT1B/1D antagonism.

brain penetratable antidepressant with high affinity to SERT and $5-\mathrm{HT}_{1 \mathrm{~A} / 1 \mathrm{~B} / 1 \mathrm{D}}$ receptors. In our design of compound RH880109, we decided to keep 2-methylpiperazine ring as the best linker identified by the authors [15-17] to link the two aromatic entities (benzoxazine and quinoline ring system).

On the other hand, we chose to use further modification to increase affinity to the target receptor while keeping the intrinsic activity to a minimum. For instance, we added a chloro group in the preferred substitution position of the quinoline ring (position 7). Additionally, we added a fluoro group on position 7 of the benzoxazine ring, and an additional methylation of the Nitrogen of the benzoxazine to design RH-880109 (Fig. 3). In designing compound RH$\mathbf{8 8 0 2 0 9}$, we chose to modify the position of the substitution of the quionline ring from quinoline-5-yl on the 2methylpiperazine linker to quionline-8-yl while keeping everything else the same (Fig. 3).

A slight modification of the linker to 3-methylpiperazine instead of 2-methylpiperazine, ethylation of nitrogen atom of the benzoxazine ring, as well as removing the halogen from both aromatic ring had lead us to the design of RH-880309. Lastly, replacing the methylated quinoline with methylated indol-4yl had lead to the design of compound RH-880409 (Fig. 3).
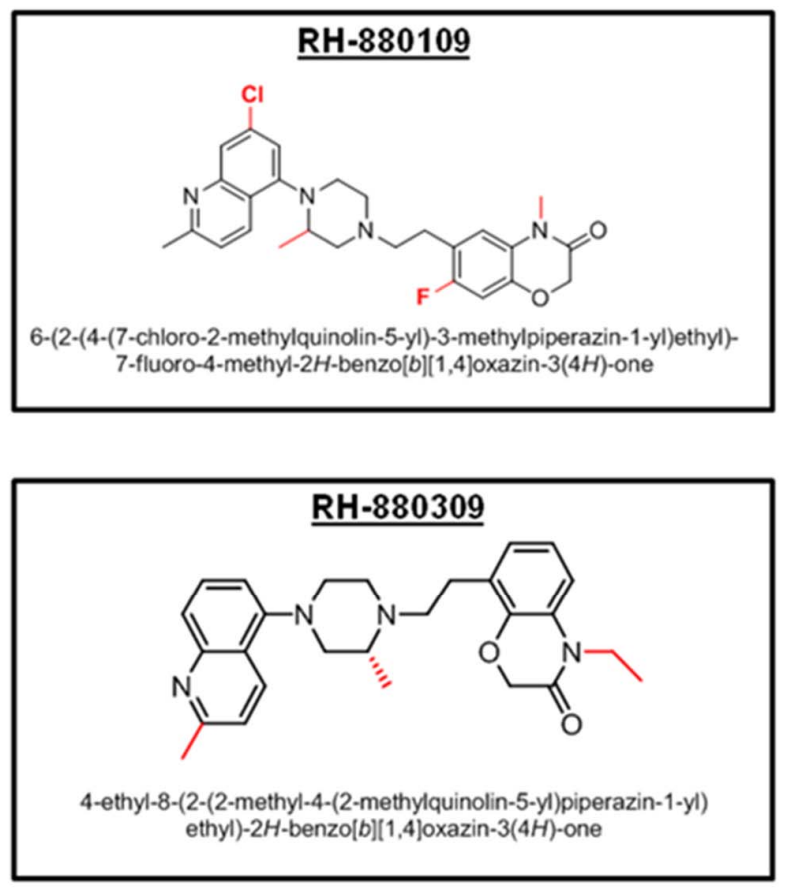

\subsubsection{Designing the "H" Series"}

Designing the " $\mathrm{H}$ " series is based on modification of the main molecular scaffold of the lead compound produced by Timms et al., Eli Lilly research in the UK [10] (Fig. 2) as a hybrid small molecule with high affinity to $5-\mathrm{HT}_{1 \mathrm{~A} / 1 \mathrm{~B} / 1 \mathrm{D}}$ receptors as well as SERT. In designing the "H" series, we kept the acetamido group as far distance from the linker since this was crucial for the potency towards $5 \mathrm{HT}_{1 \mathrm{~A} / 1 \mathrm{~B} / 1 \mathrm{D}}$ receptors [10]. However, replacing the indole with an aryl piperazine group improves selectivity towards serotonin receptors and diminishes other receptor activities.

Compound HM-590109 was designed to have a quinazoline ring with a methyl in position 2 and fluoro group in position 7 to increase the affinity while keeping the intrinsic activity to zero as indicated by the authors [10] (Fig. 4). Whereas, HM-590209 was designed to have the isosteric replacement ring of quinazoline (quionline ring) with a methyl at position 2 , and no halogen substitution. The design of HM-590309 and HM-590409 was amalgam between the two already made hybrid structures (Fig. 2).

On the other hand, HM-590309 was designed by using the benzoxazinone moiety (crucial for SERT activity) and link it to the rest of the molecule produced by Timms et al., [10] with piperazine as a linker. Whereas, HM-590409 was
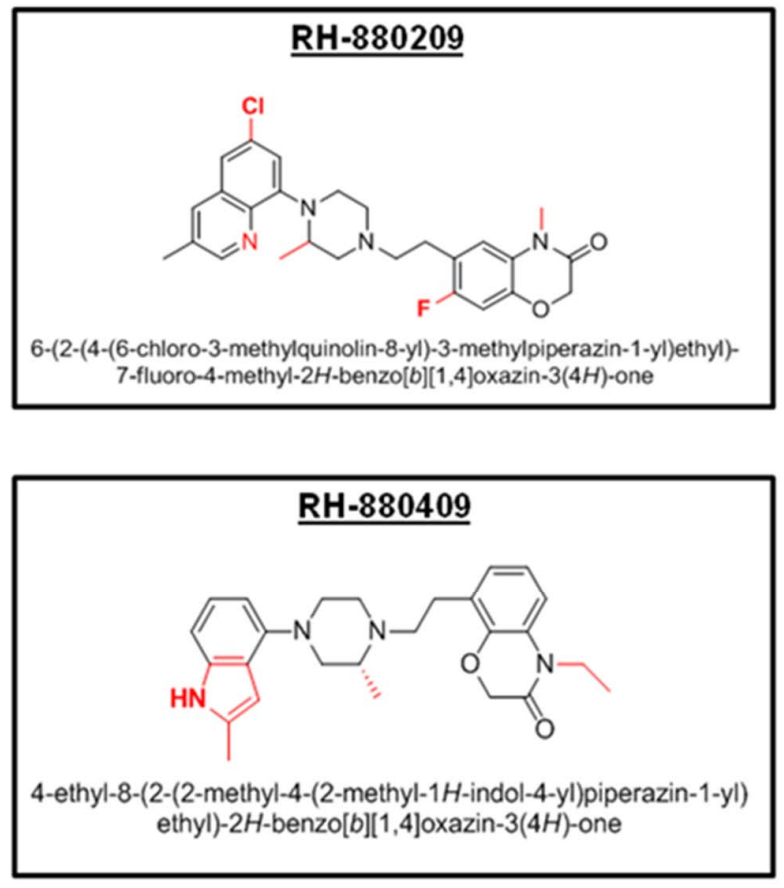

Fig. (3). Designed "R" series combining 5-HT reuptake inhibition and 5-HT1B/1D antagonism. 

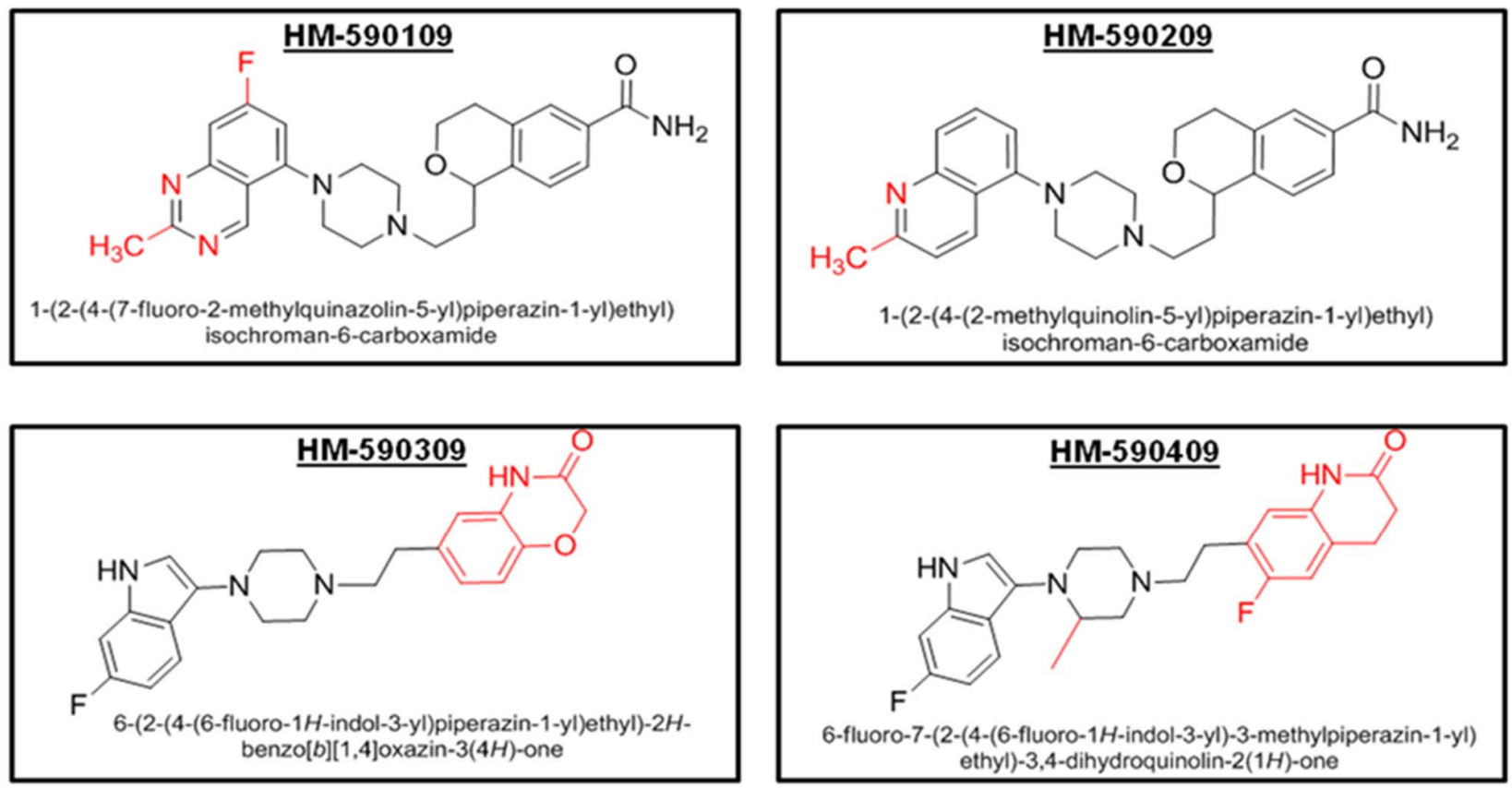

Fig. (4). Designed "H" series combining 5-HT reuptake inhibition and 5-HT1B/1D antagonism.

designed by using dihyroquinolinone ring with substituted fluoro at 7 position documented to increase in $5-\mathrm{HT}_{1 \mathrm{~A} / 1 \mathrm{~B} / 1 \mathrm{D}}$ receptor affinities with the highest affinity towards SERT $[16,17]$ as well as using 2-methylpierazine as a linker (Fig. 4).

\subsubsection{Designing the “O” Series"}

Designing the "O" series is based on the tethering technique or fragment-based drug discovery technique [18]. Tethering technique links the two molecular scaffolds believed to be responsible for the desired activity via a linker that can be easily metabolized inside the body. In series "O", we linked 1-(benzyloxy)-4-(trifluoromethyl)benzene [12] as a key pharmacophoric element of the known SERT inhibitor, Fluoxetine (blue color; Fig. 5) with functionalized phenylpiperazines as key pharmacophoric elements present in several $5 \mathrm{HT}_{1 \mathrm{~B} / 1 \mathrm{D}}$ antagonists such as O-tolylpiperazide [19] (red color; Fig. 5), WAY-100,635 [20] and BRL-15,572 [21]. The chosen linker was an amide linkage that can be easily metabolized inside the body. Novelty of all designed virtual hybrids was checked and confirmed via Scifinder Scholar ${ }^{\circledR}$ database [22].

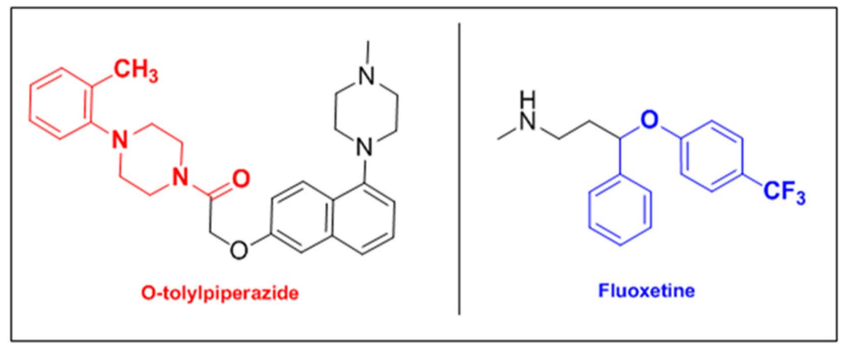

Fig. (5). Known 5-HT1B/1D antagonist; O-tolylpiperazide and known 5-HT reuptake inhibitor; Fluoxetine.

\subsection{Organic Chemical Synthesis of the Chosen Hybrid (RHO Compounds)}

The virtual hybrid to be synthesized was selected based on the following criteria:

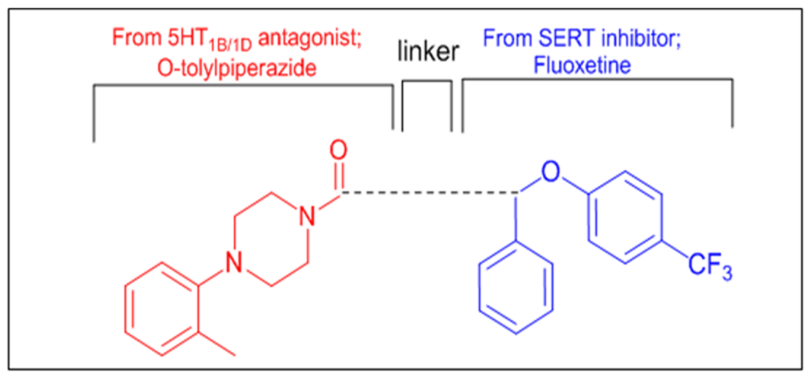

Fig. (6). Designed "O" series combining 5-HT reuptake inhibition and 5-HT1B/1D antagonism.

1. Novel and unique molecule that has never been synthesized according to the literature.

2. Its organic synthetic scheme is not more than five steps long.

3. Availability of needed chemicals and other resources.

4. Follow Lipinski's rule of five [23] which is a rule of thumb to evaluate drug likeness, and determine whether a chemical compound with a certain pharmacological or biological activity has properties that would make it a likely orally active drug in humans.

Based on the previous criteria, compound 2-Phenyl-1-(4(o-tolyl)piperazin-1-yl)-2-(4-(trifluoromethyl)phenoxy)ethanone (6) was chosen to be synthesized. In addition, because of the available resources, compound 2-Phenyl-N-(pyridin-3ylmethyl)-2-(4-(trifluoro-methyl)phenoxy)acetamide (7) was 
also synthesized as outline in the following synthetic scheme.

\subsubsection{Synthetic Scheme}

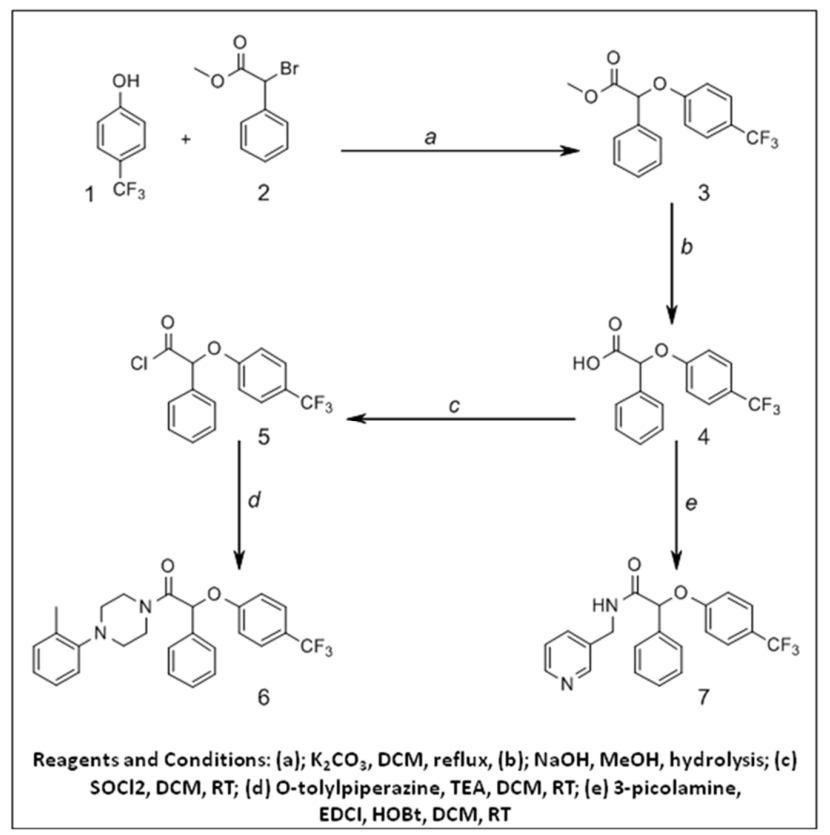

\subsubsection{Experimental}

\section{General Methods}

All reactions were performed under an Argon atmosphere. Solvent for extraction: ACS grade. Solvent for reaction: reagent grade. Reagents: Acros, Fluka or Aldrich, highest quality available. TLC: silica gel $60 F_{254}$ aluminum plates (Watman); visualization by UV absorption. Flash column chromatography was performed on Sigma-Aldrich silica gel 60 (230-440 mesh). Elemental analysis (C,H,N) was performed in the Central Laboratory Unit, Qatar University. The ${ }^{1} \mathrm{H}$ - NMR spectra were recorded at $400 \mathrm{MHz}$ (Bruker, Model: Advance) at Texas A\&M University-Qatar; $\delta$ values are given in ppm (TMS as internal standard) and $J$ values in Hz. Mass spectra were performed with Shimatzu LC/MS using electrospray ionization (ESI) and $\mathrm{MH}^{+}$is reported.

\section{Methyl 2-phenyl-2-(4-(trifluoromethyl)phenoxy)acetate (3)}

To a solution of 4-trifluoromethyl phenol (1) (0.356 g, $0.0022 \mathrm{~mol})$ in dichloromethane anhydrous $(10 \mathrm{ml})$ was added anhydrous $\mathrm{K}_{2} \mathrm{CO}_{3}(0.604 \mathrm{~g}, 0.0044 \mathrm{~mol})$, methyl $\alpha$ bromophenylacetate (2) $(0.503 \mathrm{~g}$ [0.347 ml], $0.0022 \mathrm{~mol})$. The reaction mixture was stirred at reflux temperature for 6 hours then cooled to room temperature. The reaction mixture was monitored by TLC. After completion of the reaction was indicated by TLC, $\mathrm{K}_{2} \mathrm{CO}_{3}$ was removed by filtration and the solvent was evaporated under reduced pressure, the crude residue $(0.224 \mathrm{~g})$ was then purified by column chromatography using hexane and ethyl acetate (90:10) as elution solvent. Compound (3) was afforded as a white powder (130mg, $20 \%$ yield). ${ }^{1} \mathrm{H}-\mathrm{NMR}\left(\mathrm{CDCl}_{3}, 400 \mathrm{MHz}\right)$; $\delta$ 7.580-7.595 (dd, 2H, J=6 Hz), 7.550-7.573 (d, 2H, J=9.2 $\mathrm{Hz}), 7.425-7.440(\mathrm{~d}, 3 \mathrm{H}, \mathrm{J}=6 \mathrm{~Hz}), 7.015-7.047(\mathrm{~d}, 2 \mathrm{H}$, $\mathrm{J}=12.8 \mathrm{~Hz}$ ), 5.703 (s, 1H), 3.777 (s, 3H). MS (ESI, Neg) m/z
$309\left(\mathrm{M}^{-}\right)$. Anal. Calcd for $\mathrm{C}_{16} \mathrm{H}_{13} \mathrm{~F}_{3} \mathrm{O}_{3}$ : C, 61.94; H, 4.22; O; 15.47. Found: C, 62.22; H, 4.32. (Compound RHO-OO3Supporting material).

\section{2-Phenyl-2-(4-(trifluoromethyl)phenoxy)acetic acid (4)}

To a solution of methyl 2-phenyl-2-(4(trifluoromethyl)phenoxy)acetate (3) $(0.130 \mathrm{~g}, 0.0004 \mathrm{~mol})$ in methanol $(5 \mathrm{ml})$, a solution of $\mathrm{NaOH}(0.064 \mathrm{~g}, 0.0016$ $\mathrm{mol}$ ) in $0.5 \mathrm{ml}$ water was added drop wise at room temperature, immediate yellowish coloration appears. The reaction mixture was stirred for 2 hours at room temperature. Reaction was monitored by TLC. After completion of the reaction is indicated by TLC, $\mathrm{PH}$ of the reaction mixture was adjusted to 6-7 with $2 \mathrm{~N} \mathrm{HCl}$. Evaporation of the excess solvent was performed under reduced pressure. The excess inorganic was filtered off after dissolving the crude residue in dichloromethane/methanol mixture, and then the filtrate was evaporated under reduced pressure. The target compound was afforded as a white powder $(90 \mathrm{mg}, 76 \%$ yield). MS (ESI, Neg) m/z $295.07\left(\mathrm{M}^{-}\right)$. Anal. Calcd for $\mathrm{C}_{15} \mathrm{H}_{11} \mathrm{~F}_{3} \mathrm{O}_{3}$ : C, 60.82; H, 3.74; O; 16.20. Found: C, 60.47; $\mathrm{H}, 3.69$.

\section{2-Phenyl-2-(4-(trifluoromethyl)phenoxy)acetic acid chloride (5)}

To a solution of 2-phenyl-2-(4(trifluoromethyl)phenoxy)acetic acid (4) (0.088 g, 0.0003 $\mathrm{mol})$ in anhydous dichloromethane $(5 \mathrm{ml})+$ Dimethylformamide $(0.1 \mathrm{ml})$, was added thionyl chloride $(0.177 \mathrm{~g}[0.11 \mathrm{ml}], 0.0015 \mathrm{~mol})$ at room temperature. The reaction mixture was stirred at room temperature for 2 hours, yellowish coloration appears. The reaction was monitored by TLC. After completion of the reaction is indicated by TLC, the excess solvent was performed under reduced pressure to afford yellowish solid (92 $\mathrm{mg}, 98 \%$ yield) used without further purification to the next step.

\section{2-Phenyl-1-(4-(0-tolyl)piperazin-1-yl)-2-(4- (trifluoromethyl)phenoxy)ethanone(6)}

A mixture of $o$-tolylpiperazine $\mathrm{HCl}(0.063 \mathrm{~g}, 0.0003 \mathrm{~mol})$ and triethylamine $(0.152 \mathrm{~g}[0.10 \mathrm{ml}], 0.0015 \mathrm{~mol})$ in anhydrous dichloromethane $(4 \mathrm{ml})$ was stirred at room temperature for 15 minutes. Then, a solution of 2-phenyl-2(4-(trifluoromethyl) phenoxy)acetic acid chloride (5) (0.092 $\mathrm{g}, 0.0003 \mathrm{~mol})$ in anhydrous dichloro-methane $(1 \mathrm{ml})$ was added. The reaction mixture was stirred at room temperature overnight (14 hours). The reaction was monitored by TLC. After completion of the reaction is indicated by TLC, the reaction mixture was diluted with dichloromethane $(20 \mathrm{ml})$ and sequentially washed with water, saturated $\mathrm{NaHCO}_{3}$ solution and brine and dried over $\mathrm{MgSO}_{4}$. The solvent was evaporated under reduced pressure. The crude residue was then purified by column chromatography using hexane and ethyl acetate (95:05) as elution solvent. The target compound was afforded as yellow oil (70mg, $51.4 \%$ yield). ${ }^{1} \mathrm{H}-\mathrm{NMR}$ $\left(\mathrm{CD}_{3} \mathrm{OD}, 400 \mathrm{MHz}\right) ; \delta$ 7.596-7.643 (m, 4H), 7.470-7.490 $(\mathrm{m}, 3 \mathrm{H}), 7.140-7.184(\mathrm{~m}, 3 \mathrm{H}), 7.085-7.130(\mathrm{t}, 1 \mathrm{H}, \mathrm{J}=10.8$, $7.2 \mathrm{~Hz}), 6.940-6.985$ (t, 1H, J=10.8, 7.2 Hz), 6.884-6.903 (d, $1 \mathrm{H}, \mathrm{J}=7.6 \mathrm{~Hz}), 6.332(\mathrm{~s}, 1 \mathrm{H}), 3.750-3.900(\mathrm{~m}, 3 \mathrm{H}), 3.650-$ $3.750(\mathrm{~m}, 1 \mathrm{H}), 2.770-2.920(\mathrm{~m}, 3 \mathrm{H}), 2.460-2.520(\mathrm{~m}, 1 \mathrm{H})$, 2.288 (s, 3H), MS (ESI, Pos) m/z $455\left(\mathrm{M}^{+}\right)$. (Compound RHO-006-supporting material). 


\section{2-Phenyl-N-(pyridin-3-ylmethyl)-2-(4-} (trifluoromethyl)phenoxy)acetamide (7)

A mixture of 2-phenyl-2-(4-(trifluoromethyl)phenoxy) acetic acid (4) (0.088 g, $0.0003 \mathrm{~mol}), \mathrm{N}$-(3-Dimethylaminopropyl)- $\mathrm{N}^{\prime}$-ethylcarbodiimide hydrochloride $(0.058 \mathrm{~g}$, $0.0003 \mathrm{~mol}$ ), and 1-Hydroxybenzotriazole hydrate (HOBt) $(0.041 \mathrm{~g}, 0.0003 \mathrm{~mol})$ in anhydrous dichloromethane $(1 \mathrm{ml})$ was stirred at room temperature for $15 \mathrm{~min}$. To this solution, 3-(aminomethyl) pyridine $(0.032 \mathrm{~g}, 0.00033 \mathrm{~mol})$ was added. Immediate white precipitation appears. The reaction mixture was stirred at room temperature for 24 hours). The reaction was monitored by TLC. After completion of the reaction is indicated by TLC, the reaction mixture was diluted with dichloromethane $(10 \mathrm{ml})$ and sequentially washed with water, saturated $\mathrm{NaHCO}_{3}$ solution and brine and dried over $\mathrm{MgSO}_{4}$. The solvent was evaporated under reduced pressure. The crude residue was then purified by column chromatography using dichloromethane and methanol (90:10) as elution solvent. The target compound was afforded as yellow powder (90mg, $78.2 \%$ yield). ${ }^{1} \mathrm{H}-\mathrm{NMR}$ $\left(\mathrm{CD}_{3} \mathrm{OD}, 400 \mathrm{MHz}\right) ; \delta 8.402(\mathrm{~s}, 2 \mathrm{H}), 7.550-7.628(\mathrm{~m}, 5 \mathrm{H})$, 7.372-7.438 (m, 3H), 7.288-7.330 (m, 1H), 7.149-7.171 (d, 2H, J=8.8 Hz), 5.797 (s, 1H), 4.457 (s, 2H), MS (ESI, Pos) $\mathrm{m} / \mathrm{z} 387\left(\mathrm{M}^{+}\right)$. (Compound RHO-007-supporting material).

\section{CONCLUSIONS AND OUTCOMES}

4.1. Our research study supplies an unprecedented library of novel virtual hybrid compounds combining the dual pharmacophoric profile of 5-HT reuptake inhibition and $5 \mathrm{HT} 1 \mathrm{~B} / 1 \mathrm{D}$ antagonism as a potential developer of fast acting SSRI and as anti-autism candidate.

4.2. Our study provides two novel synthesized hybrid compounds for further biological evaluation (in vitro and in vivo).

4.3. Our work herein establishes the foundation material necessary towards our ultimate goal of developing new therapeutic line of treatment for autism, where no other lines of treatment have been consistently successful.

\section{ACKNOWLEDGEMENT}

This publication was made possible by two grants from the Qatar National Research Fund under its National Priority Research Program grant number NPRP 08-252-3008 and Undergraduate Research Experience Program grant number UREP 06-014-3-005. Its contents are solely the responsibility of the authors and do not necessarily represent the official views of the Qatar National Research Fund.

\section{REFERENCES}

[1] National Health Interview Survey, Centers for Disease Control and Prevention http://www.cdc.gov/ncbddd/autism/data.html (accessed April 30, 2011).

[2] Diagnostic and Statistical Manual of Mental Disorders, 4th ed. (DSM-IV), Am. Psychiat. Assoc., Washington, 2000.

[3] Kolevzon, A.; Mathewson, K.A.; Hollander, E. Selective serotonin reuptake inhibitors in autism: a review of efficacy and tolerability. J. Clin. Psychiatry, 2006, 67, 407-414.

[4] Fineberg, N.A.; Bullock, T.; Montgomery, D.B.; Montgomery, S.A. Serotonin reuptake inhibitors are treatment of choice in obsessive compulsive disorder. Int. Clin. Psychopharmacol., 1992, 7, 43-47.
[5] Domenech, T.; Beleta, J.; Palacios, J.M. Characterization of human serotonin 1B and 1D receptors using[3H]-GR-125743, a novel radiolabelled serotonin $5 \mathrm{HT}_{1 \mathrm{~B} / \mathrm{ID}}$ receptor antagonist. NaunynSchmiedeberg's Arch. Pharmacol., 1997, 356, 328-334.

[6] Shalom, G.; Gur, E.; Van de Kar, L. D.; Newman, M. E. Repeated administration of the $5-\mathrm{HT}_{1 \mathrm{~B}}$ receptor antagonist SB-224289 blocks the desensitization of $5-\mathrm{HT}_{1 \mathrm{~B}}$ autoreceptors induced by fluoxetine. Naunyn-Schmiedeberg's Arch. Pharmacol., 2004, 370, 84-90.

[7] Sharp, T.; Gartside, S. E. Effect of a selective 5-HT reuptake inhibitor in combination with $5-\mathrm{HT}_{1 \mathrm{~A}}$ and $5-\mathrm{HT}_{1 \mathrm{~B}}$ receptor antagonists on extracellular 5-HT in rat frontal cortex in vivo. Br. J. Pharmacol., 1997, 121, 941-946.

[8] Rollema, H.; Clarke, T.; Sprouse, J. S.; Schultz, D. W. Combined administration of a $5-\mathrm{HT}_{1 \mathrm{D}}$ antagonist and a 5 - $\mathrm{HT}$ reuptake inhibitor synergistically increases 5-HT release in guinea pig hypothalamus in vivo. J. Neurochem., 1996, 67, 2204-2207.

[9] Roberts, C.; Boyd, D. F.; Middlemiss, D. N.; Routledge, C. Enhancement of 5- $\mathrm{HT}_{1 \mathrm{~B}}$ and 5-HT $\mathrm{HD}_{\mathrm{DD}}$ receptor antagonist effects on extracellular 5-HT levels in the guinea-pig brain following concurrent 5-HT $\mathrm{HA}_{\mathrm{AA}}$ or 5-HT re-uptake site blockade. Neuropharmacology, 1999, 38, 1409-1419.

[10] Timms, G. H.; Boot, J. R.; Broadmore, R. J.; Carney, S. L.; Cooper, J.; Findlay, J. D.; Gilmore, J.; Mitchell, S.; Moore, N. A.; Pullar, I.; Sanger, G. J. ; Tomlinson, R.; Tree, B. B.; Wedley, S. SAR development of a selective $5-\mathrm{HT}_{1 \mathrm{D}}$ antagonist/serotonin reuptake inhibitor lead using rapid parallel synthesis. Bioorg. Med. Chem. Lett., 2004, 14, 2469-2472.

[11] Middleton, D. S.; Andrews, M.; Glossop, P.; Gymer, G.; Jessiman, A.; Johnson, P.S.; MacKenny, M.; Pitcher, M. J.; Tang, K. ; Morgan, P. Designing rapid onset selective serotonin re-uptake inhibitors. Part 1: Structure-activity relationships of substituted (1S,4S)-4-(3,4-dichlorophenyl)-N-methyl-1,2,3,4-tetrahydro-1naphthaleneamine. Bioorg. Med. Chem. Lett., 2006,16, 1434-1439.

[12] Dorsey, J. M.; Miranda, M. G.; Cozzi, N. V.; Pinney, K. G. Synthesis and biological evaluation of 2-(4-fluorophenoxy)-2phenyl-ethyl piperazines as serotonin-selective reuptake inhibitors with a potentially improved adverse reaction profile. Bioorg. Med. Chem. Lett., 2004, 12, 1483-1491.

[13] Matzen, L.; Van-Amsterdam, C.; Rautenberg, W.; Greiner, H. E.; Harting, J.; Seyfried, C. A.; Bottcher, H. 5-HT reuptake inhibitors with $5-\mathrm{HT}_{1 \mathrm{~B} / \mathrm{LD}}$ antagonistic activity: A new approach toward efficient antidepressants. J. Med. Chem., 2000, 43, 1149-1157.

[14] Serafinowska H.T., Blaney F.E., Lovell P.J., Merlo G.G., Scott C.M., Smith P.W., Starr K.R., Watson J.M. Novel 5-HT $\mathrm{HA}_{1 \mathrm{~A} / \mathrm{B} / 1 \mathrm{D}}$ receptors antagonists with potent 5-HT reuptake inhibitor activity Bioorg. Med. Chem. Lett., 2008, 18, 5581-5585.

[15] Bromidge, S. M.; Bertani, B.; Borriello, M.; Bozzoli, A.; Faedo, S.; Gianotti, M.; Gordon, L. J.; Hill, M.; Zucchelli, V.; Watson, J. M.; Zonzini, L. 8-[2-(4-Aryl-1-piperazinyl)ethyl]-2H-1,4-benzoxazin3(4H)-ones: Dual-acting 5- $\mathrm{HT}_{1}$ receptor antagonists and serotonin reuptake inhibitors-Part II. Bioorg. Med. Chem. Lett., 2009, 19, 2338-2342.

[16] Bromidge, S. M.; Bertani, B.; Borriello, M.; Faedo, S.; Gordon, L. J.; Granci, E.; Hill, M.; Marshall, H. R.; Stasi, L. P.; Zucchelli, V.; Merlo, G.; Vesentini, A.; Watson, J. M.; Zonzini, L. 6-[2-(4-Aryl1-piperazinyl)ethyl]-2H-1,4-benzoxazin-3(4H)-ones: Dual-acting $5-\mathrm{HT}_{1}$ receptor antagonists and serotonin reuptake inhibitors. Bioorg. Med. Chem. Lett., 2008, 18, 5653-5656.

[17] Bueno, A. B; Gilmore, J; Boot, J; Broadmore, R.; Cooper, J; Findlay, J; Hayhurst, L.; Marcos, A.; Montero, C.; Mitchell, S.; Timms, G.; Tomlinson, R.; Wallace, L.; Walton, W. Napthylpiperazines with dual activity as 5HT1D antagonists and 5HT reuptake inhibitors. Bioorg. Med. Chem. Lett., 2007, 17, 33443348.

[18] Erlanson, D. A; Wells, J.A. Braisted, A.C. Tethering: FragmentBased drug discivery. Annu. Rev. Biophys. Biomol. Struct., 2004, 33, 109-223.

[19] Jorand-Lebrun, C.; Pauwels, P. J.; Palmier, C.; Chopin, P.; Moret, C.; M. Marien, M.; Halazy, S. Arylpiperazide derivatives of phenylpiperazines as a new class of potent and selective $5-\mathrm{HT}_{1 \mathrm{~B}}$ receptor antagonists. Bioorg. Med. Chem. Lett., 1997, 24, 31833188 .

[20] Davidson, C.; Ho, M.; Price, G. W. ; Jones B. J.; Stamford, J. A. (+)-WAY-100135, a partial agonist at native and recombinant 5HT1B/1D receptors. Br. J. Pharmacol., 1997, 121, 737-742. 
[21] Price, G. W.; Burton, M. J.; Collin, L. J.; Duckworth, M.; Gaster, L.; Göthert, M.; Jones, B. J.; Roberts, C.; Watson, J. M.; Middlemiss, D. N. SB-216641 and BRL-15572--compounds to pharmacologically discriminate h5-HT1B and h5-HT1D receptors. Naunyn Schmiedebergs Arch. Pharmacol., 1997, 356, 312-320.
[22] SciFinder Scholar, ${ }^{\mathrm{TM}}$ Chemical Abstracts Services database, division of American Chemical Society, 2008.

[23] Lipinski, C.A.; Lombardo, F.; Dominy, B. W.; Feeney, P.J. Experimental and computational approaches to estimate solubility and permeability in drug discovery and development settings. Adv. Drug Deliv. Rev., 1997, 23, 3-25.

(C) Ghoneim et al.; Licensee Bentham Open.

This is an open access article licensed under the terms of the Creative Commons Attribution Non-Commercial License (http://creativecommons.org/licenses/by-nc/3.0/) which permits unrestricted, non-commercial use, distribution and reproduction in any medium, provided the work is properly cited. 